\title{
Predictors of hepatitis $C$ treatment outcomes in a harm reduction-focused primary care program in New York City
}

\author{
Jacob Ziff* (1), Trang Vu, Danielle Dvir, Farah Riazi, Wilma Toribio, Scott Oster, Keith Sigel and Jeffrey Weiss
}

\begin{abstract}
Background: The social determinants of health that influence steps in the entire Hepatitis C Virus (HCV) treatment cascade must be identified to achieve HCV elimination goals. This project aimed to evaluate the association of these factors with HCV treatment completion and return for sustained virologic response (SVR) testing.

Methods: We used retrospective cohort data from our primary care-based HCV treatment program that provides comprehensive harm reduction care to those who use or formerly used drugs. Among persons who began direct-acting antiviral HCV treatment between December 2014 and March 2018, we identified two outcomes: HCV treatment completion and return for SVR assessment 12 weeks after treatment end. Several predictors were ascertained including sociodemographic information, substance use, psychiatric symptoms and history, housing instability, and HCV treatment regimen. We then evaluated associations between predictors and outcomes using univariate and multivariable statistical methods.
\end{abstract}

Results: From a cohort of 329 patients treated in an urban primary care center, multivariable analysis identified housing instability as a single significant predictor for HCV treatment completion (odds ratio [OR]: 0.3; 95\% confidence interval [CI]: 0.1-0.9). Among patients completing treatment, 226 (75\%) returned for SVR assessment; the sole predictor of this outcome was Medicaid as primary insurance (compared to other insurances; OR 0.3; 0.1-0.7).

Conclusions: Innovative strategies to help unstably housed persons complete HCV treatment are urgently needed in order to reach HCV elimination targets. Educational and motivational strategies should be developed to promote individuals with Medicaid in particular to return for SVR viral load testing, a critical post-treatment component of the HCV treatment cascade.

Trial registration Not applicable.

Keywords: Hepatitis C, Unstable housing, People who inject drugs, Medicaid, Harm reduction, Direct-acting antiviral

\section{Introduction}

In 2015, the World Health Organization (WHO) outlined global targets to eliminate Hepatitis C Virus $(\mathrm{HCV})$ as a public health threat by 2030 [1]. It did so in the context

*Correspondence: Jacob.Ziff@icahn.mssm.edu

Respectful and Equitable Access to Comprehensive Healthcare (REACH) Program, Division of General Internal Medicine, Icahn School of Medicine At Mount Sinai, 17 East 102nd Street, 7th floor, New York City, NY 10029, United States of the recent progress of promising novel direct-acting antivirals (DAAs), drugs that were shown to have unprecedented trial capacity of curing HCV [2-4]. However, recent analysis of 45 high-income countries has demonstrated that just nine are on pace to achieve these goals, and that most are not even projected to reach them by 2050-with the USA falling into this latter group [5]. This sobering reality is cause to look outside of the efficacy of DAAs in a vacuum, and calls for analyzing the original author(s) and the source, provide a link to the Creative Commons licence, and indicate if changes were made. The images or other third party material in this article are included in the article's Creative Commons licence, unless indicated otherwise in a credit line to the material. If material is not included in the article's Creative Commons licence and your intended use is not permitted by statutory regulation or exceeds the permitted use, you will need to obtain permission directly from the copyright holder. To view a copy of this licence, visit http://creativecommons.org/licenses/by/4.0/. The Creative Commons Public Domain Dedication waiver (http://creativeco mmons.org/publicdomain/zero/1.0/) applies to the data made available in this article, unless otherwise stated in a credit line to the data. 
entire $\mathrm{HCV}$ care cascade-i.e., the model used to evaluate patient retention across sequential stages of care from screening to cure. As a disease that disproportionally afflicts persons who are traditionally less engaged in the healthcare system, it is necessary to explore and sort the social determinants of health that affect patients as they undergo each step of the HCV treatment process. In doing so, providers will be able to identify and address those distinct unmet needs-out of the many that often co-occur-which have the greatest impact at specific points along the $\mathrm{HCV}$ care cascade.

The majority of HCV infections occur in marginalized and stigmatized patient populations: people who inject drugs (PWID), homeless persons, justice-involved persons, and persons with HIV co-infection. More than half of persons with injection drug use (IDU) will contract $\mathrm{HCV}$ within 5 years of starting injecting, resulting in a prevalence of over $60 \%$ among people who inject drugs [6-8]. Other non-injection substance use disorders (SUDs), like alcohol use disorder and cocaine use disorder, are also highly prevalent in the HCV-infected population and often co-occur with IDU [9]. Further, a large HCV burden exists among persons who are homeless or unstably housed, housed in neighborhoods with poor access to care, and persons with serious mental illness [10-14]. Incarceration history, or justice involvement, has also been shown to be a negative predictor of SVR, and prison populations carry a disproportionate share of $\mathrm{HCV}$-infected persons [15]. Moreover, insurance changes and terminations while on treatment are associated with poorer adherence and lower likelihood of achieving cure [16]. The demands of living with multiple intersecting stressors can affect linkage to treatment, engagement, and adherence to $\mathrm{HCV}$ therapy, ultimately interfering with the patient maintaining HCV treatment as a priority and resulting in negative outcomes [17].

In the wake of treatment innovations, such as DAAs and improved access to community-based care for SUD and $\mathrm{HCV}$ treatment in non-specialized settings, there has been significant progress and evidence of comparable cure rates being achieved in people who inject drugs as compared to other patient groups in clinical trials [1821]. Despite these advances, there remains evidence of suboptimal treatment adherence and clinical outcomes among some groups of $\mathrm{HCV}$ patients, including persons with active IDU or HIV co-infection, as a complex array of clinical and psychosocial barriers continues to deter treatment success in real world cohorts of these historically vulnerable populations [22-26].

While adherence to a full course of antiviral treatment is important for achieving viral response, an underappreciated step of the HCV care cascade is the assessment and confirmation of a sustained virologic response (SVR).
The ultimate goal of HCV treatment, SVR is achieved if the $\mathrm{HCV}$ viral load is undetectable by sensitive polymerase chain reaction (PCR) testing 12 weeks after $\mathrm{HCV}$ treatment completion. The assessment of SVR not only identifies viral relapse or reinfection but further allows for patient education on relapse prevention, repeated or future liver cancer screening, and the importance of linkage to primary care for this often vulnerable group of patients.

$\mathrm{HCV}$ treatment requires daily adherence for a usual period of 2-3 months, with follow-up to determine SVR after an additional 12 weeks. Many studies have examined viral suppression as an outcome, but more granular assessment of patient retention along the $\mathrm{HCV}$ care cascade is necessary to determine and address barriers to adherence and treatment completion that deter successful outcomes. Achievement of SVR12 is the ultimate goal of HCV treatment and it should always be included as the final step in the HCV care cascade. Despite the many advances made in the DAA era and access to $\mathrm{HCV}$ treatment in the primary care setting, interdisciplinary strategies and integrated models addressing underlying structural and individual social factors have not advanced sufficiently to achieve World Health Organization treatment elimination goals for $\mathrm{HCV}[5,27]$. Therefore, we sought to assess factors associated with $\mathrm{HCV}$ treatment completion and post-treatment SVR12 outcome assessment in our large urban cohort of people treated for $\mathrm{HCV}$ in our primary care and harm reduction-focused clinic.

\section{Methods}

\section{Program description}

In this study, we assessed potential predictors of incomplete treatment and failure to attend SVR assessment in treatment completers (a previously unstudied outcome) in a retrospective urban primary-care cohort of $\mathrm{HCV}$ infected persons treated in the Respectful and Equitable Access to Comprehensive Healthcare (REACH) Program at Mount Sinai Hospital. Located in the East Harlem neighborhood of New York City, a neighborhood with historically high HCV prevalence, the REACH Program provides medical, mental health, social work and patient navigation services to $\mathrm{HCV}$-infected persons with complex medical and psychosocial profiles [28]. The program addresses all steps in the HCV cascade of care, including community-based testing, linkage to care, retention in care, treatment readiness assessment, and reducing barriers to successful treatment completion and adherence. Building on work that has shown high rates of patients accessing medication and treatment, the program utilizes patient navigators working with a nurse and one specialty pharmacy to manage the prior authorization (PA) 
process, lessening the administrative burden on physicians and patients [29]. At each visit, including SVR12 visits, patients have access to a team of physicians, nurse practitioners, social workers, and mental health care providers.

Since 2011, the REACH program has employed the Psychosocial Readiness Evaluation and Preparation for Hepatitis C Treatment (PREP-C; prepc.org). This structured clinical assessment was developed to provide a standardized method for evaluating a patient's readiness to begin HCV treatment and helps providers identify psychosocial factors that can potentially interfere with treatment adherence; thus highlighting opportunities to intervene in order to improve these areas of functioning and educate about $\mathrm{HCV}$ infection and treatment prior to treatment initiation. The nine areas of PREP-C assessment are: motivation, information, medication adherence, self-efficacy, social support and stability, alcohol and substance use, psychiatric stability, energy level, and cognitive functioning. A summary score is assigned for each domain according to a programmed algorithm, informing providers which areas "Could Be Improved", which areas are "Satisfactory", and which areas "Need Further Evaluation".

\section{Study cohort}

All patients underwent a comprehensive initial medical visit with a corresponding electronic medical record template and a PREP-C assessment allowing for the systematic collection of all data points. A total of 329 patients who initiated treatment between December 11, 2014 to March 2, 2018 met these criteria and were included in the study. At baseline, once initiating treatment, patients were scheduled to return for assessment at weeks 2 , 4, $8,12,16$, and 24 for 12-week courses of treatment and weeks $2,4,8,12$, and 20 for 8 -week courses of treatment.

\section{Data collection}

Approval from the Institutional Review Board of the Mount Sinai School of Medicine was obtained to conduct a retrospective chart review of program databases and the medical records of all patients in the REACH program who began $\mathrm{HCV}$ medications. We extracted data from both electronic medical records (EMR) and PREP-C assessment on all 329 patients. From the EMR we collected demographics, insurance type, HCV treatment history, laboratory values reflecting liver staging, presence of diabetes and other comorbidities. We collected information on history of and current psychiatric status and illicit substance use, housing status, and incarceration history (within or outside the past 5 years as a proxy for justice involvement) from the PREP-C assessment. We ascertained the degree of liver fibrosis from the following sources, in ranked order (if a higher level of data was not available, i.e., liver biopsy, the next source was used): liver biopsy, liver transient elastrography, Fibrometer (noninvasive fibrosis index) or FIB-4 score [30]. Our primary outcome, completing treatment, was assessed in all patients and was defined as completing the prescribed course of DAAs. Our other outcome, returning for SVR, was defined as returning for viral load testing at least once 12-week post-treatment completion regardless of SVR status. Of note, while defined as simply returning for viral load testing, the vast majority of SVR12 visits included critical health components such as reinfection education, cancer screening, and linkage to primary care. The datasets used during the current study are available from the corresponding author on reasonable request.

\section{Data analysis}

We compared baseline characteristics of the cohort by treatment initiation status using the $t$ test for normally distributed continuous variables and the $\chi^{2}$ test for categorical variables, as appropriate. We were interested in several different domains as predictors of completing treatment and returning for SVR. We therefore chose variables that represented these domains from our univariable analyses a priori and fit a multivariable logistic regression model that included demographics (age, sex, and race/ethnicity), liver staging results, presence of current or lifetime psychiatric illness, presence of current or lifetime substance use, insurance type, diabetes status, housing status, incarceration history, having another comorbidity (i.e., cardiovascular disease, chronic kidney disorder, etc.), and current methadone use. We evaluated model fit statistics but did not modify the model construction based on these factors as we planned to use the model to test our conceptual model that the chosen factors may have contributed to the outcomes. All analyses were performed with STATA 13 (Stata Corporation, College Station, TX).

\section{Results}

Complete data was collected from a cohort of 329 patients who started $\mathrm{HCV}$ treatment in the REACH Program at Mount Sinai Hospital between 2014 and 2018. Our cohort was largely non-white ( $81 \%$ Table 1$)$ and had a high prevalence of history of substance use disorders (93\%) and psychiatric illness (84\%). From the original cohort of 329 patients who started HCV treatment, 302 (92\%) completed treatment. Patients who did not complete treatment were less likely to have stable housing in univariable and multivariable comparisons (Table 2: adjusted odds ratio [OR] for treatment completion: 0.3 ; $95 \%$ confidence interval $[\mathrm{CI}]: 0.1-0.9$; other 
Table 1 Baseline demographics and disease characteristics

\begin{tabular}{|c|c|c|c|c|c|c|}
\hline \multirow[t]{3}{*}{ Total n (\%) } & \multicolumn{2}{|c|}{ Treatment completion $(n=329)$} & \multirow[t]{3}{*}{$P$ value } & \multicolumn{2}{|c|}{ Return for SVR 12 test $(n=302)$} & \multirow[t]{3}{*}{$P$ value } \\
\hline & Yes & No & & Yes & No & \\
\hline & $302(92)$ & $27(8)$ & & $226(75)$ & $76(25)$ & \\
\hline \multicolumn{7}{|l|}{ Age } \\
\hline Mean & 53.5 & 53.2 & 0.882 & 54.3 & 51.3 & 0.059 \\
\hline Range & $20-77$ & $36-82$ & & $24-77$ & $20-70$ & \\
\hline $20-30$ & $19(6)$ & $0(0)$ & 0.36 & $11(5)$ & $8(11)$ & 0.076 \\
\hline $31-50$ & $85(28)$ & $11(41)$ & & $62(27)$ & $23(30)$ & \\
\hline $51-70$ & $187(62)$ & $15(56)$ & & $142(63)$ & $45(60)$ & \\
\hline $71-82$ & $11(4)$ & $1(4)$ & & $11(5)$ & $0(0)$ & \\
\hline Gender n (\%) & & & 0.862 & & & 0.53 \\
\hline Male, $n(\%)$ & $219(73)$ & $20(74)$ & & $166(73)$ & $53(70)$ & \\
\hline Female, $n(\%)$ & $83(27)$ & $7(26)$ & & $60(27)$ & $23(30)$ & \\
\hline Racelethnicity & & & 0.71 & & & 0.854 \\
\hline African American or Black, $n(\%)$ & $71(24)$ & $4(15)$ & & $54(24)$ & $17(22)$ & \\
\hline Hispanic, $n$ (\%) & $117(39)$ & $13(48)$ & & $85(37)$ & $32(42)$ & \\
\hline White, $n(\%)$ & $58(19)$ & $5(19)$ & & $43(19)$ & $15(20)$ & \\
\hline Other, $n(\%)$ & $56(19)$ & $5(19)$ & & $44(19)$ & $12(16)$ & \\
\hline Cirrhotic, n (\%) & $58(19)$ & $6(22)$ & 0.704 & $50(22)$ & $8(11)$ & 0.026 \\
\hline Insurance type & & 0.525 & & 0.033 & & \\
\hline Private, $n(\%)$ & $12(4)$ & $2(7)$ & & $11(5)$ & $1(1)$ & \\
\hline Medicaid, $n(\%)$ & $207(69)$ & $21(78)$ & & $145(64)$ & $62(82)$ & \\
\hline Medicare, $n(\%)$ & $43(14)$ & $1(4)$ & & $39(17)$ & $4(5)$ & \\
\hline Medicare + medicaid, $n(\%)$ & $39(13)$ & $3(11)$ & & $30(13)$ & $9(12)$ & \\
\hline Uninsured, $n(\%)$ & $1(0)$ & $0(0)$ & & $1(0)$ & $0(0)$ & \\
\hline Uses medicaid, $n$ (\%) & $246(81)$ & $24(89)$ & 0.33 & $175(77)$ & $71(93)$ & 0.002 \\
\hline HIV coinfection, n (\%) & $8(3)$ & $2(7)$ & 0.168 & $4(2)$ & $4(5)$ & 0.101 \\
\hline Diabetes, $n(\%)$ & $47(16)$ & $3(11)$ & 0.537 & $42(19)$ & $5(7)$ & 0.013 \\
\hline Other comorbidity, n (\%) & $182(60)$ & $14(52)$ & 0.393 & $146(64)$ & $36(47)$ & 0.008 \\
\hline Current substance use, $n(\%)$ & $90(30)$ & $10(37)$ & 0.434 & $65(29)$ & $25(33)$ & 0.496 \\
\hline Current psychiatric IIIness, n (\%) & $82(27)$ & $10(37)$ & 0.273 & $66(29)$ & $16(21)$ & 0.167 \\
\hline Lifetime substance use, $n$ (\%) & $282(93)$ & $25(93)$ & 0.129 & $208(92)$ & $74(97)$ & 0.106 \\
\hline Lifetime psychiatric Illness, n (\%) & $253(84)$ & $24(89)$ & 0.141 & $186(82)$ & $67(88)$ & 0.231 \\
\hline Housing status & & & 0.003 & & & 0.777 \\
\hline Stable, $n(\%)$ & $243(80)$ & $15(56)$ & & $181(80)$ & $62(82)$ & \\
\hline Unstable, $n(\%)$ & $59(20)$ & $12(44)$ & & $45(20)$ & $14(18)$ & \\
\hline Incarceration history & & & 0.166 & & & 0.831 \\
\hline$<5$ Years ago, $n(\%)$ & $64(21)$ & $10(37)$ & & $48(21)$ & $16(21)$ & \\
\hline$>5$ years ago, $n(\%)$ & $159(53)$ & $11(41)$ & & $117(52)$ & $42(55)$ & \\
\hline Never, $n(\%)$ & $79(26)$ & $6(22)$ & & $61(27)$ & $18(24)$ & \\
\hline Methadone use, $n(\%)$ & $196(65)$ & $20(74)$ & 0.336 & $138(61)$ & $58(76)$ & 0.016 \\
\hline
\end{tabular}

Statistically significant $p$-values ( $p$-value $<0.05$ ) were bolded

multivariate results not otherwise shown). Patients who completed treatment did not differ demographically in terms of age, gender, ethnicity, insurance type from those who did not (all $P>0.05$ ). Additionally, there was no difference in prevalence of history of or current psychiatric illness, history of or current substance use, methadone maintenance therapy, HIV coinfection, diabetes, incarceration history, or cirrhosis between those who completed treatment and those who did not (all $P>0.05)$.

We then evaluated the characteristics of the 302 patients who completed treatment and assigned the 
Table 2 Logistic regression models: (1) treatment completion; and (2) return for SVR12 testing

\begin{tabular}{|c|c|c|c|c|}
\hline \multirow[t]{2}{*}{ Predictor } & \multicolumn{2}{|c|}{ Treatment completion } & \multicolumn{2}{|c|}{ Return for SVR 12} \\
\hline & OR & $95 \% \mathrm{Cl}$ & OR & $95 \% \mathrm{Cl}$ \\
\hline Age & 1 & $0.9-1.0$ & 1 & $0.97-1.03$ \\
\hline Female & 0.8 & $0.3-2.3$ & 0.6 & $0.3-1.2$ \\
\hline \multicolumn{5}{|l|}{ Ethnicity } \\
\hline White & Reference & & & \\
\hline Black or African-American & 1.1 & $0.2-4.8$ & 0.7 & $0.3-1.8$ \\
\hline Hispanic & 0.6 & $0.2-2.1$ & 0.7 & $0.3-1.4$ \\
\hline Other & 0.8 & $0.2-3.3$ & 0.9 & $0.3-2.3$ \\
\hline Uses medicaid & 0.7 & $0.2-2.5$ & 0.3 & $0.1-0.7$ \\
\hline Cirrhosis & 0.8 & $0.3-2.3$ & 2 & $0.9-4.8$ \\
\hline Diabetes & 1.4 & $0.3-5.5$ & 2.5 & $0.9-7.2$ \\
\hline Other comorbidity & 1.2 & $0.5-2.9$ & 1.5 & $0.8-2.7$ \\
\hline Current substance use & 0.8 & $0.3-2.2$ & 1 & $0.5-1.9$ \\
\hline Current psychiatric IIIness & 0.9 & $0.4-2.2$ & 1.6 & $0.8-3.3$ \\
\hline Lifetime substance use & 2.1 & $0.3-13.7$ & 0.5 & $0.1-2.5$ \\
\hline Lifetime psychiatric Illness & 1.3 & $0.2-6.6$ & 1.6 & $0.5-4.8$ \\
\hline \multicolumn{5}{|l|}{ Incarceration history } \\
\hline Never & Reference & & & \\
\hline$<5$ years ago & 0.6 & $0.2-2.1$ & 1.3 & $0.5-3.2$ \\
\hline$>5$ years ago & 1.1 & $0.3-3.5$ & 0.9 & $0.4-2.0$ \\
\hline Methadone use & 0.6 & $0.2-2.1$ & 0.5 & $0.2-1.1$ \\
\hline Unstable housing status & 0.3 & $0.1-0.9$ & 1.2 & $0.6-2.4$ \\
\hline
\end{tabular}

*Statistically significant findings bolded

mutually exclusive outcome of either returning for SVR testing at least 12 weeks later or not (SVR12). Among those completing treatment, $226(75 \%)$ returned for SVR12 assessment and 76 (25\%) did not. Timing of SVR assessment ranged from 12 to 113 weeks, with 13 weeks being the median time period between treatment completion and returning for their post-12-week viral load testing. In univariable comparisons patients who returned for SVR were more likely to have cirrhosis $(P=0.03)$, diabetes $(P=0.01)$, or another major comorbidity (such as CHF, CKD, etc.; $P=0.008$ ). Furthermore, returning patients were less likely to have Medicaid $(P=0.002)$ and less likely to receive methadone maintenance therapy $(P=0.02)$. The two groups did not differ across any of the other variables, including common demographics, history of or current psychiatric illness, history of or current substance use, housing stability, incarceration history, and HIV coinfection (all $P>0.05$ ). In our multivariable regression model, Medicaid as primary insurance was the only independent predictor of not returning for SVR testing $(\mathrm{OR}=0.3 ; 95 \%$ CI $0.1-0.7)$.

Of the 226 patients who completed treatment and returned for SVR12 testing, 221 (98\%) achieved SVR. Of the 27 patients who did not complete treatment, 10 did eventually return for viral load testing at least 12 weeks after their anticipated treatment end date. Of those 10 patients, 7 achieved SVR (70\%; $P<0.001$ for comparison with treatment completers).

Of note, univariate testing did not demonstrate any relationship between any of the nine PREP-C domain scores and treatment completion or return for SVR12 testing; thus these data were excluded from Table 1 and logistic regression models.

\section{Discussion}

This study evaluated sociodemographic predictors of treatment completion and return for post-treatment viral load testing in a patient cohort that was predominantly non-white, with a high prevalence of incarceration history, current and past psychiatric illness, current and past substance use, and unstable housing. Patients were treated in an urban primary care clinic caring for patients with SUDs and HCV. We found that the major independent predictor of treatment completion was housing status. Lack of follow-up for confirmation of viral "cure" was common in our cohort. We identified several factors associated with non-adherence to post-treatment testing (at 12 weeks or greater), with the major predictor being Medicaid as primary insurance, a proxy for socioeconomic status. We therefore find that social determinants of health are more strongly associated with adherence of key steps of the HCV treatment cascade than demographic or comorbid factors.

In our urban $\mathrm{HCV}$ treatment program, we found that 92\% of patients completed HCV treatment, a proportion similar to other comparable patient cohorts with high rates of alcohol and substance use disorders, psychiatric illness, and on opiate agonist therapy [19, 31, 32]. We found unstable housing to be the sole independent predictor of patients not completing treatment. This finding is aligned with other studies demonstrating unstable housing to be a barrier in $\mathrm{HCV}$ care. Housing instability has been associated with non-adherence to $\mathrm{HCV}$ therapy, increased HCV acquisition, increased injecting frequency, and reduced access to addiction and HCV treatment resources [33-35]. On a larger scale, unstable housing has been identified as a social determinant of health that is more predictive of ill health than an individual's behavior related to diet, physical exercise, smoking and alcohol consumption [36, 37]. Indeed, housing instability has been shown to increase an individual's usage of emergency department and hospital services [33]. Exploring further, housing is strongly tied to other important social determinants of health, such as access to quality education and employment opportunities, access to quality nutritious foods, and exposure to violence [38]. 
Programs directed at supporting patients' housing stability have shown to decrease emergency department visits, resulting in less strain on the healthcare system [37, 39].

Other studies have found alcohol use, illicit drug use, and mental illness to be associated with HCV treatment non-completion; however these findings were not replicated in our study [21, 24, 40]. The unique structure of our program, which operates with an emphasis on educating and supporting our patients with alcohol and substance use disorders based on structured psychosocial assessment, may play a role in the lack of association of these exposures with treatment non-adherence. Indeed, past studies have demonstrated the benefits in patient experience, healthcare engagement, and overall health outcomes when healthcare is provided in a manner that destigmatizes injection drug use [41-43]. Further, the REACH clinic's all-encompassing focus on medical, psychological, and social aspects of a patient's health incarnates and validates prior calls for multidisciplinary harm reduction care models [10, 29, 44, 45]. Our findings of high treatment completion amongst these at risk populations in the REACH model of integration of primary care and harm reduction for PWID and HCV treatment is encouraging yet makes clear that additional novel strategies to educate and support patients with unstable housing to complete treatment are needed.

In the care of patients with $\mathrm{HCV}$, the assessment of treatment completion and confirmation of SVR is integral to ensure treatment success, provide post-treatment counseling and reinforce prevention of reinfection. This time in HCV care serves as an important opportunity to leverage ascertainment of $\mathrm{HCV}$ cure as a motive to continue efforts to address other comorbidities and optimize patient overall health [46]. Our study is the first we are aware of to look at the psychosocial and medical predictors of patients returning for SVR assessment. Of our patients who completed treatment, $75 \%$ returned for confirmatory viral load testing at least 12 weeks later. This suboptimal return rate is similar to others reported in similar patient cohorts [47-50]. Notably, there were multiple significant univariable associations between returning for testing and having comorbidities outside of $\mathrm{HCV}$ that required more participation in healthcare services; that is, patients who returned for testing were more likely to have had diabetes, cirrhosis, and any "other" comorbidity than patients who did not return. The strongest independent predictor, Medicaid as sole insurance, again suggests that socioeconomic determinants may have stronger impact on HCV treatment outcomes in urban HCV populations than medical, psychiatric or even substance use related factors. This is consistent with past research on associations of $\mathrm{HCV}$ health determinants with Medicaid status; persons with Medicaid have been less likely to be aware of their HCV status; had more steps in the prior authorizations process; and had longer wait times to receive prescriptions $[29,51,52]$.

Medicaid itself serves as a proxy for other social determinants of health, as research has demonstrated that most medicaid beneficiaries lack in at least one social need-i.e., adequate income, food, housing, utilities, etc.[53]. These unmet needs have been associated with an increased number of chronic conditions as well as decreased physical functioning and higher mortality [53-55]. Recognizing this, the Centers for Medicare and Medicaid Services modernized its operations in 2016 to promote practices that look beyond clinical care and to address patients' social needs [56]. While the roll-out of this "upstream" approach will vary on a state-by-state basis, the hope is that the expanded program will help bridge the gap between overall health and health care. Other more "downstream" strategies like patient navigation services and integrated harm reduction models of care-which provide patients with access to assistance programs-have been shown to improve the HCV care cascade $[29,57]$. In this study, having Medicaid insurance appears to capture a risk for becoming disengaged in health care even after successfully completing HCV treatment.

Our study was bolstered by the richness of information, both psychosocial and medical, that we were able to obtain from our program model and utilization of the PREP-C. The detailed clinical picture obtained from this information guided our comprehensive treatment strategies and is a major factor in the high rate of treatment completion that we observed. With that said, our model of care, which specializes in providing primarycare-based HCV treatment for patients who inject drugs using a harm reduction approach, may limit the generalizability of our findings. As active efforts continue to expand HCV treatment into a more generalized primary care setting, is our hope that harm reduction techniques employed by the REACH clinic do so as well. Given that we used a liberal definition of returning for SVR12-from 12 to 113-week post-treatment completion-we assigned those who did complete treatment but did not return for SVR12 testing to be lost to care; however, it is possible that they may have established care elsewhere. Also, the possibility exists that a patient could have completed treatment with us, been reinfected and subsequently retreated outside of our health system - and thus outside of our knowledge-only to return for SVR12 at a later date within our 113-week range. Furthermore, our data is from a state that provides access to HCV care to patients regardless of liver staging, psychiatric illness, alcohol or substance use, insurance status, or $\mathrm{HCV}$ reinfection. 


\section{Conclusion}

In a retrospective study of 329 majority non-white patients with high prevalence of psychiatric illness and substance use disorders treated in an urban primary care clinic specialized in providing $\mathrm{HCV}$ care to people who use drugs between 2014 and 2018, we found that housing instability and Medicaid insurance were associated with lower rates of $\mathrm{HCV}$ treatment completion and return for treatment outcome assessment, respectively. These findings can inform future HCV care models, as novel strategies are created and implemented to ensure that at-risk patients not only complete treatment but remain engaged with the healthcare system post-treatment completion.

\begin{abstract}
Abbreviations
HCV: Hepatitis C virus; SVR: Sustained virologic response; DAA: Direct-acting antiviral; PWID: People who inject drugs; IDU: Injection drug use; SUD: Substance use disorder; PCR: Polymerase chain reaction; REACH: Respectful and equitable access to comprehensive healthcare; HepCAP: Hepatitis C patient assistance program; PA: Prior authorization; PREP-C: Psychosocial readiness evaluation and preparation for hepatitis C treatment; SVR12: Sustained virologic response testing 12 weeks after treatment completion; OR: Odds ratio; $\mathrm{Cl}$ : Confidence interval.
\end{abstract}

\section{Acknowledgements}

The entire REACH Program.

\section{Authors' contributions}

JW created the PREP-C tool, provided care to our patients, and contributed to writing the manuscript. KS provided care to patients, collected PREP-C data, helped with statistical analysis, and contributed to writing the manuscript. SO designed the data extraction tool and helped extract data from the electronic medical record. WT, DD, and FR provided care to patients, collected PREP-C data, and contributed to writing the manuscript. TV provided care to patients and collected PREP-C data. JZ extracted patient data from the electronic medical record, organized and analyzed the data, and contributed to writing the manuscript. All authors read and approved the final manuscript.

\section{Funding}

The REACH Program receives grant funding from the New York State Department of Health AIDS Institute and the Robin Hood Foundation.

\section{Availability of data and materials}

The datasets used and/or analyzed during the current study are available from the corresponding author on reasonable request.

\section{Declarations}

\section{Ethics approval and consent to participate}

This study was approved by the Institutional Review Board of the Icahn School of Medicine at Mount Sinai.

\section{Consent for publication}

Not Applicable.

\section{Competing interests}

The authors declare that they have no competing interests.

Received: 23 November 2020 Accepted: 22 March 2021

Published online: 31 March 2021

\section{References}

1. WHO. Combating hepatitis B and C to reach elimination by 2030. Geneva, Switzerland: The World Health Organization; 2016.

2. Jacobson IM, McHutchison JG, Dusheiko G, Di Bisceglie AM, Reddy KR, Bzowej $\mathrm{NH}$, et al. Telaprevir for previously untreated chronic hepatitis C virus infection. N Engl J Med. 2011;364(25):2405-16.

3. Afdhal N, Zeuzem S, Kwo P, Chojkier M, Gitlin N, Puoti M, et al. Ledipasvir and sofosbuvir for untreated HCV genotype 1 infection. N Engl J Med. 2014;370(20):1889-98.

4. Kohli A, Shaffer A, Sherman A, Kottilil S. Treatment of hepatitis C: a systematic review. JAMA. 2014;312(6):631-40.

5. Razavi H, Sanchez Gonzalez Y, Yuen C, Cornberg M. Global timing of hepatitis $C$ virus elimination in high-income countries. Liver Int. 2020:40(3):522-9.

6. Hagan H, Pouget ER, Des Jarlais DC, Lelutiu-Weinberger C. Metaregression of hepatitis $C$ virus infection in relation to time since onset of illicit drug injection: the influence of time and place. Am J Epidemiol. 2008;168(10):1099-109.

7. Nelson PK, Mathers BM, Cowie B, Hagan H, Des Jarlais D, Horyniak D, et al. Global epidemiology of hepatitis $B$ and hepatitis $C$ in people who inject drugs: results of systematic reviews. Lancet (London, England). 2011;378(9791):571-83.

8. Williams IT, Bell BP, Kuhnert W, Alter MJ. Incidence and transmission patterns of acute hepatitis $C$ in the United States, 1982-2006. Arch Intern Med. 2011;171(3):242-8.

9. Irvin R, Chander G, Falade-Nwulia O, Astemborski J, Starbird L, Kirk GD, et al. Overlapping epidemics of alcohol and illicit drug use among HCVinfected persons who inject drugs. Addict Behav. 2019;96:56-61.

10. Woodrell C, Weiss J, Branch A, Gardenier D, Krauskopf K, Kil N, et al. Primary care-based hepatitis $C$ treatment outcomes with first-generation direct-acting agents. J Addict Med. 2015;9(5):405-10.

11. Hughes E, Bassi S, Gilbody S, Bland M, Martin F. Prevalence of HIV, hepatitis $B$, and hepatitis $C$ in people with severe mental illness: a systematic review and meta-analysis. Lancet Psychiatry. 2016;3(1):40-8.

12. Trager $E$, Khalili M, Masson CL, Vittinghoff E, Creasman J, Mangurian C. Hepatitis $C$ screening rate among underserved adults with serious mental illness receiving care in California community mental health centers. Am J Public Health. 2016;106(4):740-2.

13. Ford MM, Desai PS, Maduro G, Laraque F. Neighborhood inequalities in hepatitis $\mathrm{C}$ mortality: spatial and temporal patterns and associated factors. J Urban Health. 2017;94(5):746-55.

14. Nikoo N, Javidanbardan S, Akm M, Hakobyan S, Nikoo M, Kwan C, et al. Hepatitis $C$ prevalence and associated risk factors among individuals who are homeless and diagnosed with mental illness: at home/Chez Soi Study, Vancouver, BC. Eur J Public Health. 2019;29(2):242-7.

15. Wurcel AG, Burke DJ, Wang JJ, Engle B, Noonan K, Knox TA, et al. The burden of untreated HCV infection in hospitalized inmates: a hospital utilization and cost analysis. J Urban Health. 2018;95(4):467-73.

16. Beiser ME, Smith K, Ingemi M, Mulligan E, Baggett TP. Hepatitis C treatment outcomes among homeless-experienced individuals at a community health centre in Boston. Int J Drug Policy. 2019;72:129-37.

17. Cachay ER, Hill L, Torriani F, Ballard C, Grelotti D, Aquino A, et al. Predictors of missed hepatitis c intake appointments and failure to establish hepatitis C care among patients living with HIV. Open Forum Infect Dis. 2018;5(7):ofy173.

18. Rockstroh JK, Nelson M, Katlama C, Lalezari J, Mallolas J, Bloch M, et al. Efficacy and safety of grazoprevir (MK-5172) and elbasvir (MK-8742) in patients with hepatitis C virus and HIV co-infection (C-EDGE CO-INFECTION): a non-randomised, open-label trial. Lancet HIV. 2015;2(8):e319-27.

19. Cunningham EB, Amin J, Feld JJ, Bruneau J, Dalgard O, Powis J, et al. Adherence to sofosbuvir and velpatasvir among people with chronic HCV infection and recent injection drug use: the SIMPLIFY study. Int J Drug Policy. 2018;62:14-23.

20. Grebely J, Conway B, Cunningham EB, Fraser C, Moriggia A, Gane E, et al. Paritaprevir, ritonavir, ombitasvir, and dasabuvir with and without ribavirin in people with HCV genotype 1 and recent injecting drug use or receiving opioid substitution therapy. Int J Drug Policy. 2018;62:94-103.

21. Cunningham EB, Hajarizadeh B, Amin J, Litwin AH, Gane E, Cooper C, et al Adherence to once-daily and twice-daily direct acting antiviral therapy for hepatitis $C$ infection among people with recent injection drug use or current opioid agonist therapy. Clin Infect Dis. 2019. 
22. Read P, Lothian R, Chronister K, Gilliver R, Kearley J, Dore GJ, et al. Delivering direct acting antiviral therapy for hepatitis $C$ to highly marginalised and current drug injecting populations in a targeted primary health care setting. Int J Drug Policy. 2017;47:209-15.

23. Trabut JB, Barrault C, Charlot H, Carmona D, Bourdel A, Benslimane M, et al. Integrated care for the use of direct-acting antivirals in patients with chronic hepatitis $\mathrm{c}$ and substance use disorder. J Addict Med. 2018;12(5):346-52.

24. Cachay ER, Mena A, Morano L, Benitez L, Maida I, Ballard C, et al. Predictors of hepatitis $C$ treatment failure after using direct-acting antivirals in people living with human immunodeficiency virus. Open Forum Infect Dis. 2019;6(3):ofz070.

25. Rossi C, Young J, Martel-Laferriere V, Walmsley S, Cooper C, Wong A, et al. Direct-acting antiviral treatment failure among hepatitis $C$ and HIVcoinfected patients in clinical care. Open Forum Infect Dis. 2019;6(3):055.

26. Daniel KE, Saeian K, Rizvi S. Real-world experiences with directacting antiviral agents for chronic hepatitis $C$ treatment. J Viral Hepat. 2020;27(2):195-204

27. Ward JW. The Nobel Prize for discovery of HCV is a call to end hepatitis. The Lancet.

28. Joel Ackelsberg FL, Borneschlegel K, Rude E, Varma JK. Hepatitis C in New York City: state of the epidemic and action plan. In: Hygiene NYCDoHaM, editor. 2019.

29. Vu TM, Toribio W, Riazi F, Ciprian G, Gibbs N, Giardina M, et al. Increasing access to hepatitis $C$ virus medications: a program model using patient navigators and specialty pharmacy to obtain prior authorization approval. J Manag Care Spec Pharm. 2018;24(4):329-33.

30. Lurie Y, Webb M, Cytter-Kuint R, Shteingart S, Lederkremer GZ. Noninvasive diagnosis of liver fibrosis and cirrhosis. World J Gastroenterol. 2015;21(41):11567-83

31. Back D, Belperio P, Bondin M, Negro F, Talal AH, Park C, et al. Efficacy and safety of glecaprevir/pibrentasvir in patients with chronic HCV infection and psychiatric disorders: An integrated analysis. J Viral Hepat. 2019;26(8):951-60.

32. Read P, Gilliver R, Kearley J, Lothian R, Cunningham EB, Chronister KJ, et al. Treatment adherence and support for people who inject drugs taking direct-acting antiviral therapy for hepatitis C infection. J Viral Hepat. 2019;26(11):1301-10

33. Kim C, Kerr T, Li K, Zhang R, Tyndall MW, Montaner JS, et al. Unstable housing and hepatitis $C$ incidence among injection drug users in a Canadian setting. BMC Public Health. 2009;9:270.

34. Harris $M$, Rhodes T. Hepatitis $C$ treatment access and uptake for people who inject drugs: a review mapping the role of social factors. Harm Reduct J. 2013;10:7.

35. Fortier E, Sylvestre MP, Artenie AA, Minoyan N, Jutras-Aswad D, Roy E, et al. Associations between housing stability and injecting frequency fluctuations: findings from a cohort of people who inject drugs in Montreal Canada. Drug Alcohol Depend. 2020;206:107744.

36. Raphael D, Raphael D. (eds). Social determinants of health: Canadian perspectives, 2nd edn. Toronto: Canadian Scholars' Press; 2009.

37. Forchuk C. Social determinants of health: housing and income. Healtcare Q. 2016;18:27-31.

38. Braveman P, Egerter S, Williams DR. The social determinants of health: coming of age. Annu Rev Public Health. 2011;32:381-98.

39. Forchuk C. Homelessness, housing, and mental health: finding truths, creating change. Toronto: Canadian Scholars' Press Inc; 2011.

40. Brown A, Welzel TM, Conway B, Negro F, Brau N, Grebely J, et al. Adherence to pan-genotypic glecaprevir/pibrentasvir and efficacy in HCV-infected patients: a pooled analysis of clinical trials. Liver Int. 2020:40(4):778-86.
41. Ahern J, Stuber J, Galea S. Stigma, discrimination and the health of illicit drug users. Drug Alcohol Depend. 2007;88(2-3):188-96.

42. Latkin C, Davey-Rothwell M, Yang JY, Crawford N. The relationship between drug user stigma and depression among inner-city drug users in Baltimore, MD. J Urban Health. 2013;90(1):147-56.

43. Muncan B, Walters SM, Ezell J, Ompad DC. "They look at us like junkies": influences of drug use stigma on the healthcare engagement of people who inject drugs in New York City. Harm Reduct J. 2020;17(1):53.

44. Cooper CL, Mills EJ. Therapeutic challenges in hepatitis C-infected injection drug using patients. Harm Reduct J. 2006;3:31.

45. Cunningham EB, Hajarizadeh B, Amin J, Hellard M, Bruneau J, Feld JJ, et al. Reinfection following successful direct-acting antiviral therapy for hepatitis C infection among people who inject drugs. Clin Infect Dis. 2020.

46. Kim NJ, Magee C, Cummings C, Park H, Khalili M. Liver disease monitoring practices after hepatitis $C$ cure in the underserved population. Hepatol Commun. 2018;2(10):1274-83.

47. Marshall MC, Herrera JL. Lack of patient compliance in real-world practice negatively affects sustained viral response rates to direct acting agent therapy for hepatitis C. Dig Dis Sci. 2018;63(12):3228-32.

48. Stewart RA, MacDonald BR, Chu TC, Moore JD, Fasanmi EO, Ojha RP. Ledipasvir/sofosbuvir effectively treats hepatitis c virus infections in an underserved population. Dig Dis Sci. 2018;63(12):3233-40.

49. Tran AN, Sachdev R, Fricker ZP, Leber M, Zahorian T, Shah B, et al. Intensive pharmacy care improves outcomes of hepatitis $C$ treatment in a vulnerable patient population at a safety-net hospital. Dig Dis Sci. 2018;63(12):3241-9.

50. Coyle C, Moorman AC, Bartholomew T, Klein G, Kwakwa H, Mehta SH, et al. The hepatitis $C$ virus care continuum: linkage to hepatitis $C$ virus care and treatment among patients at an urban health network, Philadelphia, PA. Hepatology. 2019;70(2):476-86.

51. Bourgi K, Brar I, Baker-Genaw K. Health disparities in hepatitis C screening and linkage to care at an integrated health system in Southeast Michigan. PLOS ONE. 2016;11(8):e0161241.

52. Chhatwal J, Chen Q, Bethea ED, Hur C, Spaulding AC, Kanwal F. The impact of direct-acting anti-virals on the hepatitis $C$ care cascade: identifying progress and gaps towards hepatitis C elimination in the United States. Aliment Pharmacol Ther. 2019;50(1):66-74.

53. Thompson T, McQueen A, Croston M, Luke A, Caito N, Quinn K, et al. Social needs and health-related outcomes among medicaid beneficiaries. Health Educ Behav. 2019:46(3):436-44.

54. Blazer DG, Sachs-Ericsson N, Hybels CF. Perception of unmet basic needs as a predictor of mortality among community-dwelling older adults. Am J Public Health. 2005;95(2):299-304.

55. Sachs-Ericsson N, Schatschneider C, Blazer DG. Perception of unmet basic needs as a predictor of physical functioning among community-dwelling older adults. J Aging Health. 2006;18(6):852-68.

56. Machledt D. Addressing the social determinants of health through medicaid managed care. The Commonwealth Fund. 2017.

57. Keast SL, Holderread B, Cothran T, Skrepnek GH. Assessment of the effect of an enhanced prior authorization and management program in a United States Medicaid program on chronic hepatitis C treatment adherence and cost. J Am Pharm Assoc. 2018;58(5):485-91.

\section{Publisher's Note}

Springer Nature remains neutral with regard to jurisdictional claims in published maps and institutional affiliations. 